\title{
CORRIGENDUM
}

\section{Novel cross talk between MEK and S6K2 in FGF-2 induced proliferation of SCLC cells}

OE Pardo, A Arcaro, G Salerno, TD Tetley, T Valovka, I Gout and MJ Seckl

Oncogene (2014) 33, 5740; doi:10.1038/onc.2014.369

\author{
Correction to: Oncogene (2001) 20, 7658-7667; doi:10.1038/ \\ sj.onc.1204994
}

We have discovered and would like to unreservedly apologise for some errors in a paper we submitted to J Biol Chem in 2001 (published in April 2002, 277(14): 12040-6) that relate to our Oncogene paper that was published in Sep 2001 (20(52): 7658-67). Most of these errors concern duplication of small amounts of negative control data that appeared in the Oncogene manuscript and that were reused in the $\mathrm{J}$ Biol Chem paper without proper attribution to the original publication in Oncogene. Thus, Figures $6 \mathrm{~A}, \mathrm{~B}$ and $3 \mathrm{~A}$ (right panel) from our Oncogene paper were duplicated as Figures 2B, C and 4A (upper panel) in the J Biol Chem paper, respectively. These data show that FGF-2 does not activate
$\mathrm{PI} 3 \mathrm{~K} / \mathrm{PKB}$ signalling in $\mathrm{H}-510$ cells or Erk1/2 in $\mathrm{H}-69$ cells. To rectify this, we have retrospectively asked permission from Oncogene to reproduce Figures $6 \mathrm{~A}$ and $\mathrm{B}$ in $\mathrm{J}$ Biol Chem and have provided a fresh replacement experiment to $\mathrm{J}$ Biol Chem for Figure $4 \mathrm{~A}$ (upper panel). In addition, we noted that the wrong lamin B loading controls were used in Figure $3 \mathrm{~A}$ and the lower panel of Figure 4A of the J Biol Chem paper and appeared to have been incorrectly duplicated from separate experiments presented in the Oncogene paper. We have therefore repeated these experiments and presented the replacement figures to J Biol Chem. Importantly, the results confirm our original findings. Moreover, none of the errors have any impact on the interpretation of the data or conclusions presented in our original Oncogene manuscript. 